\title{
Modification of Glycosylated Haemoglobin Concentration during Artificial Endocrine Pancreas Treatment of Diabetics
}

\author{
Evidence for a Short-term Effect on $\mathbf{H b A}_{\mathbf{I}(a+b+c)}$ Levels \\ G. Bolli, Maria G. Cartechini ${ }^{1}$, P. Compagnucci ${ }^{1}$, F. Santeusanio ${ }^{1}$, M. Massi-Benedetti, G. Calabrese, \\ A. Puxeddu, and P. Brunetti \\ Institute of Medical Pathology and ${ }^{1}$ Clinical Medicine, University of Perugia, Perugia, Italy
}

\begin{abstract}
Summary. In order to verify whether or not insulininduced blood glucose control can acutely lower glycosylated haemoglobin levels, $\mathrm{HbA}_{\mathrm{I}(\mathrm{a}+\mathrm{b}+\mathrm{c})}(\mathrm{HbAI})$ was measured in 11 diabetics before, during and after 3 days of treatment with an "artificial endocrine pancreas" (Biostator). Initially 5 patients were in fair glycaemic control (group A), while the other 6 showed poor control (group B). HbAI levels decreased significantly after 3 days in both groups A (from $9.6 \pm 0.2 \%$ to $8.5 \pm 0.3 \%$, mean \pm SEM, $\mathrm{p}<0.05$ ) and $\mathrm{B}$ (from $13.7 \pm 0.2 \%$ to $12.6 \pm 0.3 \%$, $\mathrm{p}<0.05)$. A further HbAI decrease was observed until day 60 following Biostator treatment, during which period glycaemic control inproved, as assessed by fasting and post-lunch plasma glucose values and daily glycosuria determined every 10 days.

These results suggest that increased HbAI levels may be reversed early by strict blood glucose control during a 3 day period. It is concluded that $\mathrm{HbAI}$ levels not only reflect long-term glycaemic control, but also recent acute variations in mean blood glucose values.
\end{abstract}

Key words: Glycosylated haemoglobin, artificial endocrine pancreas, continuous blood glucose monitoring, subcutaneous insulin treatment.

The total glycosylated haemoglobin ( $\mathrm{HbAI})$ level in poorly controlled diabetics is markedly increased in comparison with normal and diabetic subjects in good control $[1,2]$. It shows good correlation with various indices of glycaemic control [3]. It is generally accepted that $\mathrm{HbAI}$ constitutes a useful guide to diabetes management $[4,5]$ and routine simultaneous determination of $\mathrm{HbAI}$ and blood glucose in diabetics has been proposed [6].
At present, it is well known that the HbAI levels decrease slowly after several weeks of improved glycaemic control in diabetics $[3,7,8,9,10]$. Few results are, however, available concerning changes in $\mathrm{HbAI}$ in the course of short-term blood glucose variations in diabetic patients $[11,12]$, although many studies relating the rapidity of the $\mathrm{Hb}$ glycosylation process to the ambient glucose concentration have been reported in vitro $[13,14,15]$. Thus, it is not presently known whether acute therapeutic manipulation of blood glucose levels significantly affects HbAI concentrations.

We have therefore investigated $\mathrm{HbAI}$ levels in eleven diabetics before, during and after three days of glucose controlled insulin infusion using a so-called "artificial endocrine pancreas" (GCIIS).

\section{Materials and Methods}

\section{Patients and Protocol}

Eleven diabetics were recruited for the study after full explanation of its methods and purposes. Their clinical features are shown in Table 1. The patients were not taking any therapy other than insulin, except for case 2, who was given only oral hypoglycaemic agents. In each patient plasma glucose (fasting and $90 \mathrm{~min}$ postlunch) was determined at least twice in the month before admission at fortnightly intervals. A glycaemic profile (plasma glucose concentration measured fasting, post-breakfast, pre- and postlunch, pre- and post-dinner, and at bed-time), and daily glycosuria were determined in all patients soon after hospitalization. The mean daily plasma glucose level was also calculated. Since therapy was not changed when patients entered the hospital, the results were taken to reflect the degree of control before admission.

Patients were divided in two groups according to the degree of their glycaemic control. Group A consisted of 5 diabetics with fair control (plasma glucose: fasting less than $150 \mathrm{mg} / 100 \mathrm{ml}$, postlunch less than $200 \mathrm{mg} / 100 \mathrm{ml}$, mean daily less than $170 \mathrm{mg} /$ $100 \mathrm{ml}$; glycosuria less than $15 \mathrm{~g} / 24 \mathrm{~h}$ ). Group B consisted of 6 diabetics in poor control (plasma glucose: fasting more than 


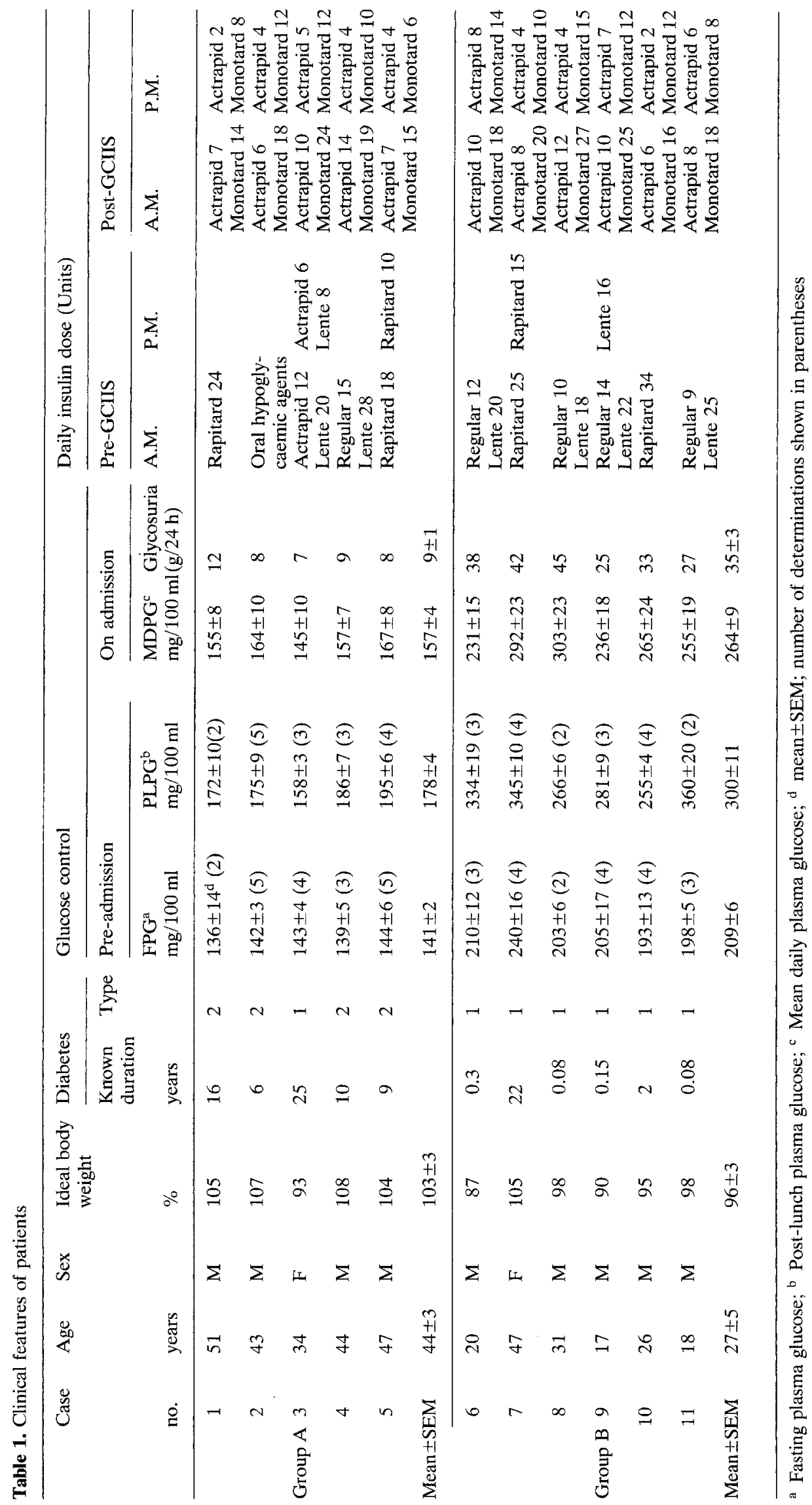


$190 \mathrm{mg} / 100 \mathrm{ml}$, post-lunch more than $250 \mathrm{mg} / 100 \mathrm{ml}$, mean daily glucose more than $230 \mathrm{mg} / 100 \mathrm{ml}$; glycosuria more than $25 \mathrm{~g} /$ $24 \mathrm{~h}$ ). The clinical diagnosis of Type 1 versus Type 2 diabetes mellitus was established at the time of diagnosis according to the following criteria: sudden onset, significant ketonuria, body weight below $110 \%$ of the ideal for sex and height (Metropolitan Life Insurance Table). All Type 1 diabetics were aged under 25 years at the time of diagnosis, except for case 8 , who was aged 31 . After obtaining informed consent, patients were connected to a GCIIS (Biostator, Miles Inc. Elkhart, Indiana) for three days. Highly purified porcine insulin ("Actrapid" monocomponent insulin, Novo Industri, Copenhagen, Denmark) was infused by a computerized feed-back system through an indwelling catheter placed in a proximal antecubital vein, while simultaneous blood glucose monitoring was performed via another catheter in a distal vein of the same forearm. Approximately $40 \mathrm{ml}$ blood was withdrawn per day for glucose monitoring. Haematological parameters (haematocrit, haemoglobin, red blood cell and reticulocyte count) were determined every $24 \mathrm{~h}$ of GCIIS treatment.

After 3 days treatment patients were given appropriate subcutaneous insulin treatment (two daily injections of "Actrapid" and "Monotard" Novo m. c. insulin mixture) based on the information obtained during GCIIS control. Blood samples for glucose measurement and $24 \mathrm{~h}$ urine collections were obtained on days 10 , $20,40,60,90,150$ after Biostator treatment.

\section{Glycosylated Haemoglobin Measurement}

Venous blood for HbAI determination was collected on admission, two days before and at $0,24,48$ and $72 \mathrm{~h}$ after the start of GCIIS control; thereafter on days 10,20,40,60,90,150 after the end of Biostator treatment. $\mathrm{HbAI}\left(\mathrm{HbA}_{\mathrm{I}(\mathrm{a}+\mathrm{b}+\mathrm{c})}\right)$ was determined chromatographically by a modification [16] of the Kynoch and Lehmann method [17]. The red blood cells of each sample were washed, haemolyzed with distilled water soon after blood withdrawal, and immediately stored at $+4^{\circ} \mathrm{C}$ for at least four days before chromatographic isolation. Storage of haemolysate for up to seven days at $+4^{\circ} \mathrm{C}$ gave results identical to those of freshly prepared haemolysate (coefficient of variation in normal subjects, $1.5 \%$ ), confirming previous reports [18]. Samples obtained from each patient during GCIIS treatment were determined together in duplicate. Several glass chromatographic columns (internal diameter $2 \mathrm{~cm}$ ) were filled with Bio Rex $70(5 \mathrm{~cm}$ high) after careful equilibration in $41 \mathrm{mmol} / 1$ phosphate buffer, $10 \mathrm{mmol} / \mathrm{KCN}$, pH 6.75 (Developer No. 6) [1]. Variable amounts of haemolysate $(0.3-0.5 \mathrm{ml})$ were added to the top of the resin and eluted with the same buffer at $18-20^{\circ} \mathrm{C}$. One hundred $\mathrm{ml}$ containing glycosylated fractions $A_{I a}, A_{I b}, A_{I c}$ were collected, while the $A_{o}$ fraction was eluted with $100 \mathrm{ml}$ of buffer phosphate $0.15 \mathrm{~mol} / 1, \mathrm{pH} 6.40$. The purity of the $\mathrm{HbA}_{\text {Ic }}$ chromatographic peak was tested by electrophoresis of the globin chains, as previously reported by Cirotto et al $[19,20]$. HbAI concentration was expressed as $\%$ total haemoglobin eluted. The interassay coefficient of variation of this method in our laboratory is $1.2 \%$ for the assay at high $\mathrm{HbAI}$ level $(15-16 \%)$ and $1.8 \%$ at low HbAI level $(6-7 \%)$. By this method we have found total glycosylated haemoglobin $\left(\mathrm{HbA}_{\mathrm{I}(\mathrm{a}+\mathrm{b}+\mathrm{c})}\right)$ to correlate closely with its principal glycosylated $A_{\mathrm{Ic}}$ fraction $(\mathrm{r}=$ $0.97, \mathrm{p}<0.001)$. Therefore, as the $\mathrm{HbA}_{\mathrm{I}(\mathrm{a}+\mathrm{b}+\mathrm{c})}$ determination is more rapid, all results of the study are expressed as total glycosylated haemoglobin. Normal $\mathrm{HbA}_{\mathrm{I}(\mathrm{a}+\mathrm{b}+\mathrm{c})}$ values were determined in duplicate in 40 healthy subjects with normal plasma glucose OGTT response [21] aged from 15 to 58 years ( $42 \pm 2$ years, mean $\pm \mathrm{SEM}$ ).

Plasma and urinary glucose levels were determined with a Beckman Glucose Analyzer.

Analysis of variance (ANOVA) was used to assess differences of $\mathrm{HbAI}$ levels before, during and after GCIIS therapy and during

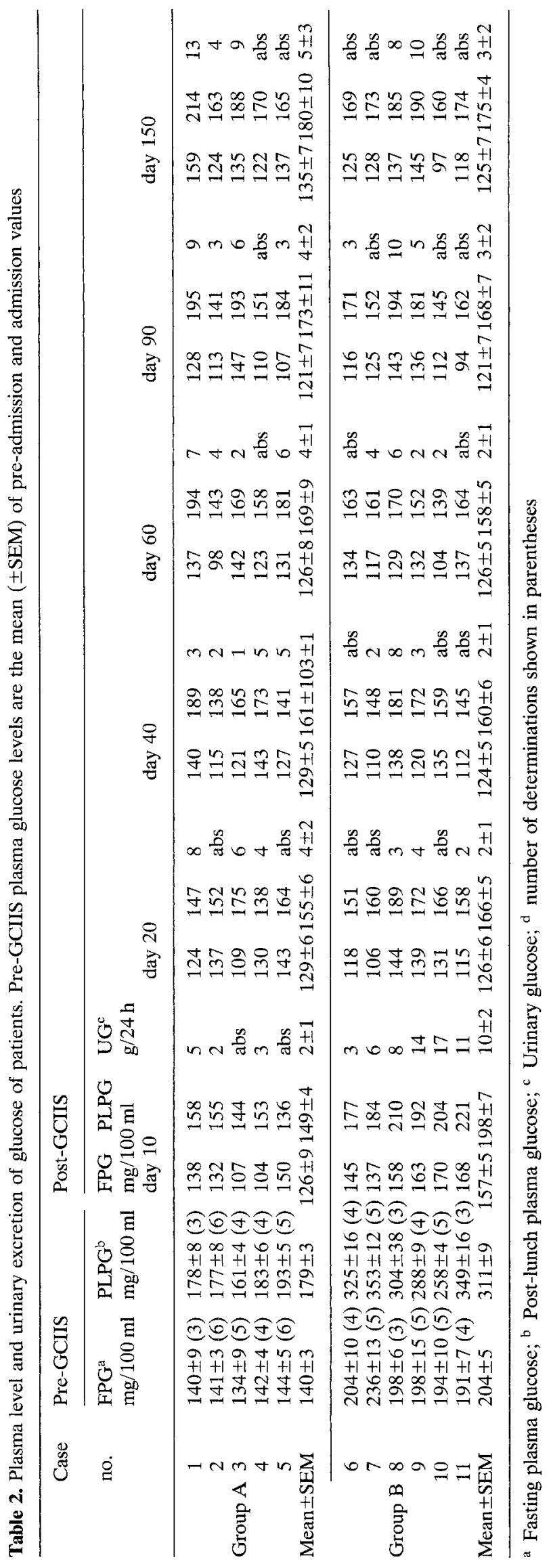




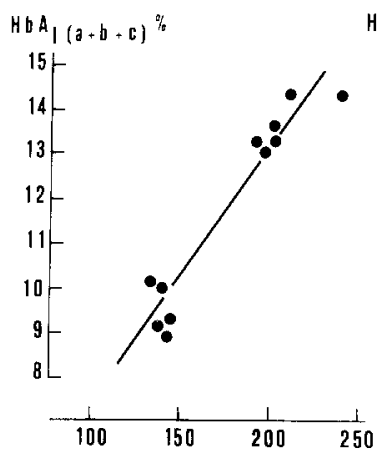

FASTING PG

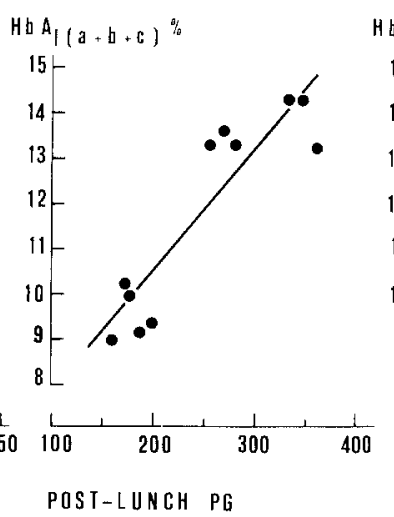

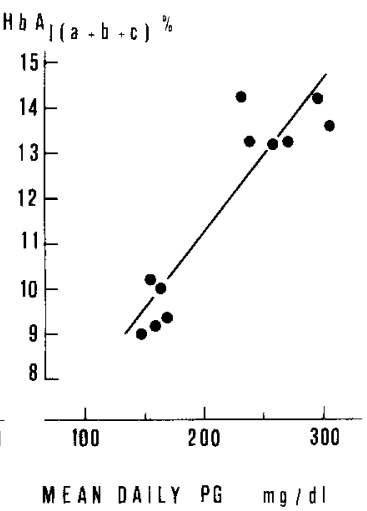

Fig. 1. Significant correlation between $\mathrm{HbAI}$ and plasma glucose (PG) levels in 11 diabetics investigated in the study. Fasting and $90^{\prime}$ post-lunch $P G$ are mean values of at least 2 preadmission determinations. Mean daily PG was calculated based on plasma glucose profile on admission (fasting, 90' post-breakfast, $30^{\prime}$ pre- and $90^{\prime}$ post-lunch, $30^{\prime}$ pre- and $90^{\prime}$ post-dinner and at 12 p. m.). Statistical significance estimated by Kendall's rank method: fasting PG $\mathrm{p}<$ 0.01 ; post-lunch $\mathrm{PG} \mathrm{p}<0.05$; mean daily $P G p<0.05$

Table 3. Glycosylated haemoglobin levels in diabetics with poor (group B) and fair (Group A) glycaemic control on admission and before, during and after $72 \mathrm{~h}$ of GCIIS control

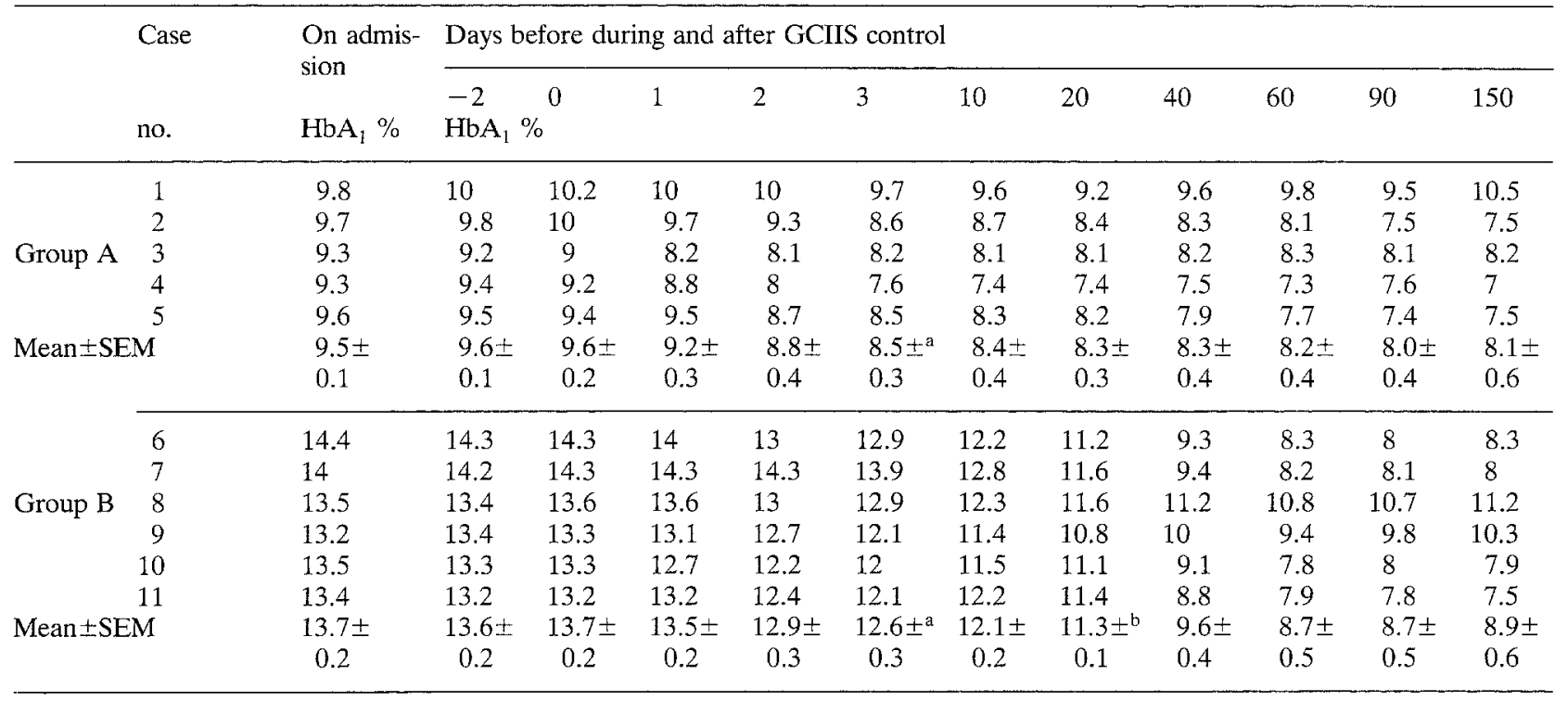

${ }^{\mathrm{a}} \mathrm{p}<0.05$ (vs day 0 ); ${ }^{\mathrm{b}} \mathrm{p}<0.01$ (vs day 3 ) by analysis of variance

SC insulin treatment up to day 150 after GCIIS control. ANOVA was applied also to the regression between $\mathrm{HbAI}$ and time during GCIIS treatment. Paired and unpaired Student's t-tests were used where appropriate. Correlations beween $\mathrm{HbAI}$ and plasma glucose level were calculated using Kendall's rank method.

\section{Results}

Blood glucose decreased to the normal range in all patients after a few hours [ 1 to 4 ] of GCIIS treatment and remained continuously controlled both during fasting $(80-110 \mathrm{mg} / 100 \mathrm{ml})$ and post-lunch $(120-140 \mathrm{mg} / 100 \mathrm{ml})$. No significant changes in haematocrit, haemoglobin, red blood cell and reticulocyte count were observed after $72 \mathrm{~h}$ blood withdrawal by GCIIS for continuous glucose monitoring. Glycaemic control improved in each patient during appropriate subcutaneous insulin therapy following GCIIS treatment as assessed by fasting and post-lunch plasma glucose values and daily glycosuria (Table 2).

On admission HbAI levels were markedly increased in all patients in comparison with normal subjects $(11.8 \pm 0.7 \%$ vs $6.4 \pm 0.1 \%$, mean $\pm \mathrm{SEM}$, $\mathrm{p}<0.001)$ and showed significant correlations with fasting $(r=0.65, p<0.01)$, post-lunch $(r=0.57$, $\mathrm{p}<0.05)$ and mean daily $(\mathrm{r}=0.61, \mathrm{p}<0.05)$ plasma glucose values (Fig. 1). HbAI levels were higher in diabetics with poor glycaemic control than in diabetics in fair control $(13.7 \pm 0.2 \%$ vs $9.6 \pm 0.2 \%$ of groups $\mathrm{B}$ and $\mathrm{A}$, respectively; $\mathrm{p}<0.001$ ).

Changes in HbAI levels in the course of three days normoglycaemia achieved with the GCIIS and thereafter up to day 150 after Biostator treatment 
are summarized in Table 3. After 24 and $48 \mathrm{~h}$ of GCIIS treatment no statistically significant difference was present in HbAI levels. In contrast, $\mathrm{HbAI}$ decreased significantly after $72 \mathrm{~h}$ from $9.6 \pm 0.2 \%$ to $8.5 \pm 0.3 \%$ in group $\mathrm{A}$ and from $13.7 \pm 0.2 \%$ to $12.6 \pm 0.3 \%$ in group B ( $\mathrm{p}<0.05$ in both groups). The mean $\mathrm{HbAI}$ level decrease was about $1 \%$ in the two groups $(11 \%$ decrease in group $\mathrm{A}$ and $8 \%$ in $\mathrm{B}$, HbAI basal value being taken as $100 \%$ ). The decrease of glycosylated haemoglobin (dependent variable) during $72 \mathrm{~h}$ of GCIIS control (independent variable) was confirmed by the significant linear regression slope (group A: $\mathrm{p}<0.025$; group $\mathrm{B}$ : $\mathrm{p}<$ $0.01)$. The HbAI improvement continued after stopping GCIIS and changing to appropriate subcutaneous insulin therapy (Fig. 2). In group B HbAI levels showed a significant decrease vs day 3 of GCIIS control on day 20 of conventional treatment $(p<0.01)$. A further HbAI decrease was observed until day 60 .

\section{Discussion}

It is now well established that increased HbAI levels represent a post-synthetic effect of chronic hyperglycaemia [22]. HbAI shows a significantly lower level in poorly controlled diabetics after 3-4 weeks of subcutaneous appropriate insulin treatment $[3,8,9]$ or 2 weeks treatment with a portable insulin-infusion pump [10]. Recently we observed a significant decrease in HbAI in five untreated diabetics on the 10th day of conventional insulin treatment with a more marked fall in the following weeks [7]. It, therefore, seems likely that the HbAI level decreases only after several days or weeks of improved glycaemic control and that it represents an index of mean blood glucose value over a period of many weeks before examination [5].

Extensive results of short-term effects of appropriate insulin treatment on the $\mathrm{Hb}$ glycosylation process have not been described in diabetics. However, a careful investigation of this problem necessarily implies preliminary methodological considerations.

Firstly, diabetics must be carefully selected so that fixed $\mathrm{HbAI}$ levels are demonstrated for several days before the start of investigation. Secondly, an accurate and highly reproducible method for determination of glycosylated haemoglobin is mandatory. Thirdly, and perhaps more difficult to realize, a suitable index of glycaemic control following appropriate insulin therapy must be considered.

In our study the first and second criteria were met, while the third was attempted using a glucose controlled insulin infusion system.

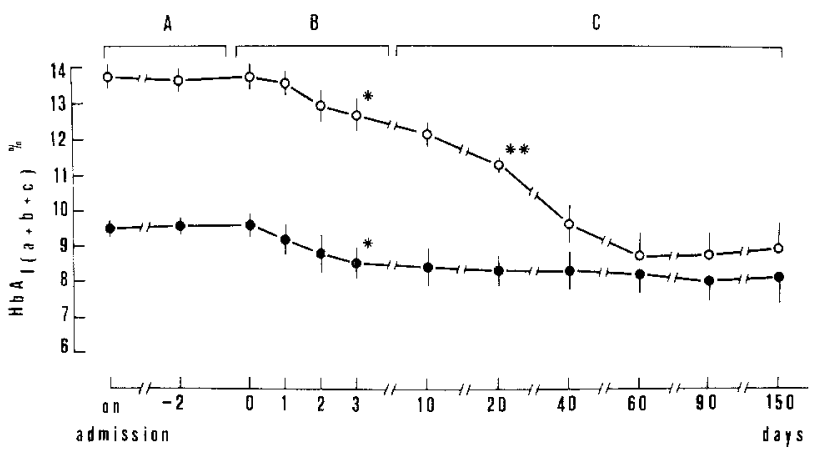

Fig. 2. $\mathrm{HbAI}$ levels (mean $\pm \mathrm{SEM}$ ) in 11 diabetics (• group $\mathrm{A}, \mathrm{n}=$ 5; group $B, n=6$ ) before (A), during GCIIS control (B) and on carefully planned SC insulin treatment (C). Analysis of variance: $* p<0.05$ vs day $0 ; * * p<0.01$ vs day 3

Under these conditions we observed a slight, but progressive decrease in $\mathrm{HbAI}$ levels in diabetics, previously in either poor or fair glycaemic control, in the course of three days of GCIIS therapy. The results suggest that some metabolic consequences of diabetic hyperglycaemia, such as enhanced $\mathrm{HbAI}$ levels, may be reversed early by strict control of blood glucose values during a three day period and they confirm our recent observation of a significant $\mathrm{HbAI}$ decrease in four untreated diabetics after $48 \mathrm{~h}$ of GCIIS therapy [11].

The mean $\mathrm{HbAl}$ decrease during GCIIS treatment was about $1 \%$ in both groups. This rapid change requires explanation. The mean red blood cell renewal in the course of three days accounts for about $2.5 \%$ of the total circulating erythrocytes in normal subjects and thus only $2.5 \%$ of total haemoglobin will be synthesized in this period. In the hypothetical condition of absent or markedly reduced glycosylation rate, a $\mathrm{HbAI}$ decrease should be observed equal to $9.6 \%$ (group A) or $13.7 \%$ (group B) of the renewed haemoglobin, that is $0.3-0.4 \%$ of total glycosylated haemoglobin after 3 days. On the other hand it has been recently demonstrated that erythrocyte half-life as measured by ${ }^{51} \mathrm{Cr}$ labelling is reduced in diabetics with poor glycaemic control [23]. Thus the $\mathrm{Hb}$ renewal rate should be more rapid in these patients than in normals and might explain, at least in part, the difference between hypothetically expected and observed $\mathrm{HbAI}$ decrease during GCIIS treatment. Acute blood withdrawal was probably of little importance in this regard, based on the reticulocyte count and other haematological parameters, which did not significantly change before and after GCIIS treatment. Moreover, although the iron kinetic data of Bunn et al. [22] show that the HbAI non-enzymatic glycosylation process is slightly reversible in vivo, the 3 days $\mathrm{HbAI}$ de-glycosylation percentage is very small and 
it would be hard to calculate a quantitative estimate of the $\mathrm{HbAI}$ de-glycosylated fraction over this period [24]. Therefore it does not seem possible to consider the HbAI decrease during GCIIS treatment as a consequence of fast de-glycosylation process, as recently proposed by Svendsen et al. [12], whose hypothesis is in sharp contrast with many in vitro and in vivo results $[22,11,25,26]$.

In our patients the HbAI decrease continued until day 60 after GCIIS treatment during conventional but carefully designed insulin therapy. This result agrees with the idea that haemoglobin is glycosylated very slowly, continuously, and nearly irreversibly during the entire life span of the red blood cell [22]. The HbAI decrease in poorly controlled diabetics confirms previous reports $[3,7,8,9$, $10]$ and is a tangible proof of reversibility of a biological abnormality following chronic hyperglycaemia. A significant HbAI decrease, however, was observed even in diabetics initially in fair control, confirming that in these patients also $\mathrm{HbAI}$ is a reliable indicator of the improved control achieved with more appropriate insulin therapy.

We conclude that the HbAI level not only reflects the long-term effects of previous glycaemic control in diabetics, but is also sensitive to recent acute variations in mean blood glucose levels, as those realized during GCIIS treatment.

Acknowledgements. The authors are deeply indebted to Dr. H. Franklin Bunn for reviewing the manuscript and for his instructive comments. Thanks are also due to Dr. Carlo Cirotto for his valuable help in chromatographic isolation of $\mathrm{HbAI}$. This work was supported by grant No. 78.02009.04 from the Italian National Research Council (C.N.R.).

\section{References}

1. Trivelli L A, Ranney H M, Lai H-T (1971) Haemoglobin components in patients with diabetes mellitus. $\mathrm{N}$ Engl J Med 284: 353-357

2. Gabbay K H, Hasty K, Breslow J L, Ellison R C, Bunn HF, Gallop P M (1977) Glycosylated haemoglobins and long-term blood glucose control in diabetes mellitus. J Clin Endocrinol Metab 44: 859-864

3. König R J, Peterson C M, Jones R L, Saudek C, Lehrman M, Cerami A (1976) Correlation of glucose regulation and hemoglobin $A$ in diabetes mellitus. $N$ Engl J Med 295: $417-420$

4. Gonen B, Rubenstein A H, Rochman H, Tanega S, Horwitz DL (1977) Haemoglobin A1: an indicator of the metabolic control of diabetic patient. Lancet II: 734-737

5. Gonen B, Rubenstein A H (1978) Haemoglobin A1 and diabetes mellitus. Diabetologia 15: 1-8

6. Davis R E, Nicol D J (1978): A rapid simplified method for routine measurement of glycosylated haemoglobin. Lancet II: 350-351

7. Bolli G, Compagnucci P, Cartechini M G, Panara F, Cirotto C, Brunetti $P(1978)$ Effect of insulin treatment on glycosylated hemoglobin levels in diabetes mellitus. IRCS Med Sci 6: 366
8. Ditzel J, Kjaergaard J-J (1978) Haemoglobin A tion after initial insulin treatment for newly discovered diabetes. Br Med J I: 741-742

9. Fraser D M, Smith A F, Gray R S, Borsey D Q, Sinclair ME, Clarke B F, Duncan L J P (1979) Glycosylated haemoglobin concentrations in newly diagnosed diabetics before and during treatment. Br Med J I: 979-981

10. Tamborlane WV, Sherwin RS, Genel M, Felig P (1979) Restoration of normal lipid and aminoacid metabolism in diabetic patients treated with a portable insulin-infusion pump. Lancet I: $1258-1261$

11. Bolli G, Cartechini MG, Compagnucci P, Cirotto C, MassiBenedetti M, Santeusanio F, Brunetti P (1979) Glycosylated hemoglobin levels in untreated diabetics during three days of artificial beta-cell treatment. IRCS Med Sci 7: 30

12. Svendsen P A, Christiansen J S, Welinder B, Nerup J (1979) Fast glycosylation of haemoglobin. Lancet I: 603

13. Haney D N, Bunn HF (1976) Glycosylation of hemoglobin in vitro: affinity labeling of haemoglobin by glucose-6-phosphate. Proc Natl Acad Sci USA 73: 3534-3538

14. Flückiger R, Winterhalter KH (1976) In vitro synthesis of hemoglobin $\mathrm{A}_{1 \mathrm{c}}$. Febs Lett 71: 356-360

15. Stevens V J, Vlassara H, Abati A, Cerami A (1977) Nonenzymatic glycosylation of hemoglobin. J Biol Chem 252: 2998-3002

16. Cirotto C, Cartechini M G, Compagnucci P, Bolli G, Panara F, Santeusanio F, Brunetti $P$ (in preparation) An improved chromatographic method for determination of $\left.\mathrm{HbA}_{\mathrm{I}}(\mathrm{a}+\mathrm{b}+\mathrm{c}\rangle\right)$ diabetic patients

17. Kynoch P A M, Lehmann H (1977) Rapid estimation (21/2 hours) of glycosylated haemoglobin for routine purposes. Lancet II: 16

18. Cole R A, Soeldner J S, Dunn P J, Bunn H F (1978) A rapid method for the determination of glycosylated hemoglobins using high pressure liquid chromatography. Metabolism 27: 289-301

19. Cirotto C, Panara F, Compagnucci P, Cartechini M G, Bolli G, Santeusanio $F$ (1978) How to distinguish hemoglobin A from hemoglobin $\mathrm{A}_{1 \mathrm{c}}$. IRCS Med Sci 6: 374

20. Cirotto C, Arangi I, Compagnucci P, Cartechini M G, Bolli G, Nicoletti I (1978) Characterization of $A_{1 a}, A_{1 b}$ and $A_{1 c}$ hemoglobin by electrophoresis of the globin chain. IRCS Med Sci 6: 375

21. Fajans S S, Conn JW (1959) Early recognition of diabetes mellitus. Ann N Y Acad Sci 82: 208-218

22. Bunn HF, Haney D N, Kamin S, Gabbay K H, Gallop P M (1976) The biosynthesis of human haemoglobin $\mathrm{A}_{1 c}$ J Clin Invest 57: 1652-1659

23. Peterson CM, Jones R L, König R J, Melvin E T, Lehrman ML (1977) Reversible hematologic sequelae of diabetes mellitus. Ann Intern Med 86: 425-429

24. Bunn HF (Personal comunication)

25. Welch S G (1979) Fast glycosylation of haemoglobin. Lancet I: 728

26. Bolli G, Cartechini M G, Compagnucci P, Massi-Benedetti M, Santeusanio F, Brunetti P (1979) Fast glycosylation of haemoglobin. Lancet I: 1143-1144

Received: April 3, 1979,

and in revised form: August 10, 1979

Dr. G. Bolli

Istituto Patologia Medica Università

Policlinico Monteluce

I-06100 Perugia

Italy 